\title{
Christiane Sand et Sylvie Delaigue Moins, Maurice fils de George Sand
}

\section{Lise Sabourin}

\section{OpenEdition}

1 Journals

\section{Édition électronique}

URL : http://journals.openedition.org/studifrancesi/6038

DOI : ERREUR PDO dans /localdata/www-bin/Core/Core/Db/Db.class.php L.34 : SQLSTATE[HY000]

[2006] MySQL server has gone away

ISSN : 2427-5856

\section{Éditeur}

Rosenberg \& Sellier

\section{Édition imprimée}

Date de publication : 1 mai 2011

Pagination : 195-196

ISSN : 0039-2944

\section{Référence électronique}

Lise Sabourin, "Christiane Sand et Sylvie Delaigue Moins, Maurice fils de George Sand ", Studi Francesi [En ligne], 163 (LV | I) | 2011, mis en ligne le 30 novembre 2015, consulté le 07 janvier 2021. URL: http://journals.openedition.org/studifrancesi/6038; DOI : https://doi.org/ERREUR PDO dans / localdata/www-bin/Core/Core/Db/Db.class.php L.34 : SQLSTATE[HY000] [2006] MySQL server has gone away

Ce document a été généré automatiquement le 7 janvier 2021.

\section{(c)}

Studi Francesi è distribuita con Licenza Creative Commons Attribuzione - Non commerciale - Non opere derivate 4.0 Internazionale. 


\title{
Christiane Sand et Sylvie Delaigue Moins, Maurice fils de George Sand
}

\author{
Lise Sabourin
}

\section{RÉFÉRENCE}

CHRISTIANE SAND et SYLVIE DELAIGUE MOINS, Maurice fils de George Sand, [36500] Vendoeuvres, Lancosme éditeur / Editions du Patrimoine Centre des Monuments nationaux, 2010, pp. 383.

1 En prélude à l'ouverture au public de son atelier sous les combles de Nohant, Christiane Sand et Sylvie Delaigue-Moins ont réuni dans ce splendide volume l'œuvre de Maurice Sand, dont la polyvalence prend désormais une visibilité assurée. On savait en effet la proximité entre la mère et le fils, préservée après le mariage en 1862 avec Lina Calamata, la fille choisie par le cœur, là où Solange avait déçu; on connaissait le théâtre façonné et décoré, les marionnettes conçues et cousues en famille; on était informé des romans restés un peu dans l'ombre maternelle (Callirhoé en 1864, Le Coq aux cheveux d'or en 1867, Miss Mary en 1868, Mademoiselle Azote en 1870). Mais ce livre à la belle maquette colorée, orné de photographies impeccables, permet, au fil de la biographie, de mieux prendre conscience de la multiplicité d'intérêts de Maurice en héritier des goûts et activités de «l'honnête homme» classique (préface de Georges Buisson, pp. 9-22).

Il conserve les soins d'un maître futur du domaine (capitaine des pompiers de La Châtre, il deviendra tout naturellement maire de Nohant en 1848) qui gère ses terres et ses paysans, veille au bonheur de ses filles et de ses amis. Amateur d'entomologie, de botanique et de géologie, ce touche-à-tout génial prend la peine de publier Le Monde des papillons en 1867, illustré par ses soins (voir pp. 168-192) et une Notice sur un atelier de silex taillés (pp. 339). Mais, pressenti dessinateur dès le plus âge par une «mère absolue, amie complaisante» (selon l'expression de Sand elle-même; voir les carnets de croquis 
d'enfance, pp. 39-45), il choisit, à l'école de Delacroix de 1840 à 46, la carrière artistique.

Comme Eugène Lambert, futur "peintre des chats» qu'il rencontre alors, il pratique les études d'animaux (pp. 108-113), après celles d'académie (pp. 68-73) et d'anatomie (pp. 86-90). Son intérêt pour les scènes militaires (pp. 78-83, notamment Soldats au repos) se combine avec les croquis de paysages dès Majorque (pp. 56-59), à Guillery (pp. 65-67), puis en Berry (pp. 74-77), lors de ses voyages en Italie, en Algérie (pp. 238-241) et aux États-Unis (dans son journal Six Mille Lienes à toute vapeur en 1862, pp. 242-249). Sa fantaisie se plaît aussi bien aux marivaudages (pp. 114-119) et aux personnages de la commedia dell'arte (qu'il recense précieusement et dessine pour Masques et bouffons en 1860, pp. 212-235) qu'aux bonshommes en carton (pp. 49-53), aux jeux de carte, aux bandes dessinées et aux rébus humoristiques (pp. 94-107).

4 Convaincu comme sa mère de rassembler les souvenirs du merveilleux paysan avant sa disparition par l'instruction et l'exode urbain, il illustre Mœurs et coutumes du Berry en 1851 et trouve dans la collation des Légendes rustiques en 1858 matière à des dessins inspirés (pp. 200-210) dont le fantastique est puissant (voir notamment Les Lupins et La Grand Bête, pp. 203). Mais sa carrière d'illustrateur (un Rabelais illustré, pp. 122-130) n'a pas l'occasion de se déployer (malgré - ou à cause? - des trois tomes d'Euvres complètes de sa mère pour Hetzel quand il reprend le flambeau de Johannot après sa mort en 1852; voir une illustration pour Spiridion, p. 195).

5 C'est donc la vie des marionnettes qui va rassembler ses talents multiples. À partir des simples marottes inventées pour un théâtre du Guignol en 1847 avec Alexandre Manceau, toute une vie s'organise, de l'atelier de création au castelet, puis au petit théâtre où tous les familiers de Nohant interprètent des pièces en avant-première, distraient les invités ou animent le carnaval avec les villageois. Affiches, invitations, dessins des costumes (pp. 132-142), maquettes de décors (pp. 346 et 353), croquis (pp. 366-367) puis confection des marionnettes (pp. 320-321) occupent désormais la maisonnée au gré des débats de direction de troupe entre Balandard et Boquillon (pp. 146-156). Leur vie est si prégnante que la correspondance sandienne les mentionne dans ses affections comme des personnes vivantes (voir pp. 300-311); elles permettront à Maurice orphelin de surmonter son désarroi en poursuivant à Passy leurs représentations (pp. 352-357) dont le succès mondain n'est sans doute pas indifférent à la fortune continue de leur renommée. 